\title{
The role of social worker in the success of social integration for disabled children Analytical study in the reality of Jordanian society
}

\author{
Dr: Yousef Al-Shurman \\ Associate Professor, Department of Social Sciences, University Faculty of Ajloun, Al- \\ Balqa Applied University, Ajloun - Jordan
}

\begin{abstract}
The study aimed at understanding the role of the social worker in the process of social integration for disabled children in Jordan through different programs and institutions because of the local and global awareness of the necessity for integrated programs for disabled children. It also aimed at integrating and activating children in the process of rehabilitation in order to regain their interaction, adaptation and productivity; so the special disabled can play an active and positive role in their community. The study found that the social worker job with disabled children and with their environment that they interact with; play a significant role in developing the social skills for disabled children and in preparing the society to accept them as an active member in their society.
\end{abstract}

Key Words: The role, disabled children, social integration.

DOI: $10.7176 /$ RHSS/10-8-05

Publication date: April $30^{\text {th }} 2020$

Introduction

The insider of the disabled cases of children found that the idea of social integration for this segment has given rise to a lot of controversy among worker in the field of social services or special education; all between supporter and opponent. However, the studies regarding the social integration for disabled children have been come out after the spreading of academic integration programs for these children in school accompanied by the positive attitude towards special needs children. Nevertheless, the truth about the social integration cannot be separated from the rise of social awareness rights for this segment; which was historically considered marginal. This also has been woven by many negative stereotypes especially in Arab society, including Jordanian society.

The society itself does not view the disabled as a healthy person, but rather as a dependent person. As a result, the disabled person feels isolated and incapable, and prevents him from integrating on all forms from confronting society. The main goal of the social service in the field of care and rehabilitation is to deal with the individuals and their families, and to help the caring and rehabilitation institution to achieve their goals. The role of social worker focuses on balancing, bringing about change and achieving the social justice. His work is initiated using intervention social methods with individual, family, groups and local community in order to solve all the problems that facing the disabled on personal, family and community level.

The social integration of disabled children; which is intended to integrate the disabled children into normal social life through two basic methods. First, they are integrated through housing and residency and then rehabilitate them to live independently. Second, they are integrated through work as a productive member, which enhances the social acceptance. (Alrousan, 1998: 30).

The disabled children in Jordan and in the world

It should be pointed out that most studies that attempted to define the disabled in different fields were essentially similar, as it looked at the disabled as a the person with physical or mental disability compared to able-bodied peers, and about $10 \%$ of the world total population is included in this definition.

Disability can be seen as a social pattern and this pattern is often an obstacle. In most societies, disabled people are identified as a problem or as people with a problem. Here, the disabled child is seen through what he is unable to do rather than what he can do. Disability prevents children from doing certain activities. Therefore, they suffer because they are compared with able-bodied children. (UNIFEM, 2014).

A person with a disability is defined as a person who has long-term physical, sensory, intellectual, mental, psychological or neurological impairment, which, as a result of interaction with other physical and behavioral barriers, may hinder performance by such person of one of the major life activities or hinder the exercise by such person of any right or basic freedom independently. Disability ranges between simple, medium or severe. (Statistics, 2017) 
It should be noted that there are two trends in defining the disability among researchers; the first trend defines the disabled person is as a person with a particular disability in one of his organs, which makes him unable to adopt with his society normally. Disability in this case means that the individual cannot meet the requirement of his natural role in life related to his age, sex and social and cultural characteristics; as a result of an injury or disability in performing physiological or psychological functions. In this sense, different types of disability like mental, auditory, visual, physical disability and learning difficulties are included.

The second trend: disability is not limited to the individual's physical disability, but rather it includes any situation that prevent the individual from performing his normal role in the society; even if it is not due to a physical impairment. As a result, the disabled is the person whose chance to find a job, maintain job or get promoting in his job, is greatly reduced because of physical impairment that is not legally recognized. The disabled person, hence, may be subject to an autistic or isolation that makes him unable to adopt with his surrounding society members despite being heathy person. This definition also includes what is called behavioral disorder and intercultural struggles of a person; indeed, disability is not a result of single cause but the result of combination of causes, healthy, genetic, cultural and social factors which vary from one society to another and from time to time.

Sociologist, medicine scholar and psychologist look forward to come up with a new term instead of the word disabled, after noticing the small difference between the disabled and the able-bodied people. Every person has a lack of some aspects and a distinction of some others. The sum of these in the individual's personality makes him able to adopt with his society if he is guided in a way that matches his abilities and the society capabilities to the extent that the able-bodied in one society might be disabled in another society.

In recent year, the world's attention has been drawn to the need and care of disabled. The research and studies have confirmed that the disabled people have the capacities, aptitudes and potentials, which are not less than ordinary people. Therefore, their own private schools and institutions have been established to help them investing what they have of capacities, aptitudes and potentials that enable them to have their natural life like others, because disability will never stop the circle of life. (United Nations, 2012)

Disability, however, is a situation that limits the person from performing one or more basic duties in the normal life like self-care, social relation or activities within the normal limits. It also means the inability to be selfdependence and making him in need for the aid of others and for special education to overcome his disability or looking for new way of social integration.

According to the international classification of functioning, disabilities and health, the disability includes impairment, activity restrictions and impediment of participation. So the disability is an interaction between people with health conditions like (poliomyelitis, down syndrome and depression), and personal factors and surrounding environments like (negative attitudes such as, difficulties in accessing buildings, public transportation, and the lack of social supports).

Worldwide, there are more than 1000 million people experience disabilities; they form more than $15 \%$ of the total population (one-seventh of the total population is disabled). The number of disabled people will continue to increase because of ageing and suffering chronic diseases in the world. The national disability patterns are influenced by health conditions, environmental factors and some other factors - like road accidents, falls, violence and humanitarians emergencies such as natural disasters, conflicts diet and drug abuse.

Disability has a disproportionate impact on women, elderly people and poor. In addition, children from poor families, ethnic minority groups, displaced people and immigrants are at much greater risk of disability. Refugees, immigrants and impaired prisoners face special challenging in accessing services. The impairment is increasing in low-income countries more than high-income countries. In 2013, the United Nations General Assembly noted that more than $80 \%$ of disabled people live in developing countries.

Despite the magnitude of this problem, there is a lack of awareness and scientific information about disability problems. There are few documents showing aggregations and analyzes of the ways in which countries have developed policies and responses to meet the needs of persons with disabilities. (World Health Organization)

The Jordan Statistics Department is a pioneering institution in providing statistics about disabled in Jordan. It provides real-time indicators about this segment in corporation with Higher Council for the Rights of Persons with Disabilities according to the latest global indicators. That is for monitoring their reality and providing a 
reference for policy makers in Jordan to develop policies for this segment because they are citizens who need to have their own rights.

According to the Jordan Public Statistics Department 2017, 11.1\% of Jordanians over the age of five are disabled. The highest disability was visual, and then mobility impairment, after that auditory impairment and the least was communication with others. (General, statistics, 2017)

The problem of disabled people in Jordan is not mainly in getting a job, but they also suffer from problems related to practical practices and application of legislation. In addition, the social awareness of integrating this segment is weak, as many of disabled people face difficulties in getting a job that lead many of them to launch a campaign to get supporters and advocacy through modern means of communication, distribution publications and posters, organizing workshop and seminars. Concerned people believe that through these campaign and activities disabled people have been recognized as not surpluses human. "Many of them have been employed, especially women who never get a job for many reasons like difficult circumstances in the village, lack of training or lack of knowledge of laws and other different reasons." DW News / 2012.

\section{Specialist and Social Integration}

The social service profession seeks to help the disabled to restore interaction, adaptation and production. Its goals in the field of disability are to contribute to adjusting the attitude of society to recognize the disabled as a human group that has the right of normal life; also, it aims to deal with them as normal people who have rights and duties. In addition, it aims to deal with them based on their mental and physical abilities so that they can have the social required confidence.

We cannot deny historically the feeling of shame and powerlessness that the Jordanian family felt because of having a disabled member which force the family to isolate completely the disabled children socially. It was normal to deny the existence of disabled child for social consideration like negative social stigma especially if they have unmarried girls. Nevertheless, we cannot deny the marked change in positive society trends towards disabled children because of widespread of public social awareness of the rights of disabled, and widespread of education in Jordanian society. (Waisbern. 1980)

A realistic view of Jordanian society suggests a significant change in Jordanian attitude towards disabled people, which is due to number of factors related to society awareness, including the educational and financial level of families. (Alryhani, 1978)

Social service also seeks to raise public awareness in society about the nature and the types of problems of disabled, how to accept and help them through positive relations with them in the general community frame. Bringing new concepts towards disabled children is a fundamental reason to integrate them socially away from the feeling of fear and denial. As a result, the fear on family members is no longer acceptable because they have a disabled child no matter what the type of disability is. It must be recognized that he is a normal person but he has disability. (Hussein, 1988)

The social service also seeks to provide vocational rehabilitation services and opportunities for disabled people. In addition, it seeks to provide appropriate educational opportunities according to their physical and mental abilities. Here, we should pointed out that the community efforts in Jordan have resulted in providing compulsory job opportunities for them in government sectors through a quota in each institution; however, the opportunities in the private sector still weak. (Higher Council for the Rights of Persons with Disabilities, 2015)

The real integration of disabled people comes through finding the appropriate job opportunities for disabled people and what is needed of rehabilitation and legal potential that ensures their public life and work. (Disabled people law: 2017)

The social service seeks to provide related social service opportunities needed by disabled through qualified social workers. The service also extends to their families to teach them how to deal and care for the disabled. The social development of the disabled is a development of its capacity on thinking and cooperating, which helps him to adopt and cope with his community. (Al-Serhan, 2006)

All social-service customer problems ultimately result from problems of failure to perform a social function or not getting the satisfaction needed to perform social roles. Thus, it creates non-adaptation in the social environment. The social worker through his knowledge seeks the highest level of adaptation. In another words, 
the customers should retake an active role. The disabled must recognize his problem first through the social worker, and then he should face it. Moreover, the social worker should inform the disabled about the strength and the weaknesses that he has, and then invest that in the required social integration process. The specialist often uses a development mechanism and development knowledge with the disabled because it helps to play a role, adopt and then integrate him. (Abdul Hameed, 2018)

It should be pointed out that most disabled children are vulnerable to unsupportive environment, which increase their sense of inferiority and vulnerability, and reduce their educational opportunities and participation and deepen their inferiority and diversity. As a result, social concepts of disability must be reviewed, and a vision of the reality of disabled in natural environment must be constructed. And we believe that the social worker within the occupational intervention teams is the real supporter to rebuild these typical stereotypes in a way that allow society to understand the needs of disabled and then to accept their existence first and then integrate them into these environments.

Social worker can work on three levels simultaneously to integrate the disabled people starting from disabled, his family and finally the community level. First, at the level of disabled child, the social worker must do a comprehensive study to know his needs and skills, to develop his skills, and to redirect them to support the disabled personality. After that, he works to activate the role of assistive devices which in turn reduce the intensity of psychological disorder, and work to support the disabled socially and psychologically and help him them to eliminate their problem, especially those related to social interactions. In addition, it benefits from laws and legislation that support disabled in different fields and institutions, so that the disabled then is pushed into new relationships with disabled or heathy people, which will help to create new social experience needed by disabled.

The family needs to move on to work on the family levels to recognize their social and economic realities, as the family is basic supporter for the individual, the family is concerned about knowing all the details of disability and how to deal with them. Working with the family needs require the social workers to strengthen the principle of acceptance and building positive relationships with the families. The social workers later works to get rids of negative feeling towards disability. The family can start integrating the disabled into the family and then being integrated into large social environment, which is linked to the preparation of joint program for families and disabled and to the successful role of the family in socialization, which is the early development of the social integration. At the highest level; the community level; there should be ideas contradict with the negative ideas towards the disabled people. So society members should be aware of disability and accepting it, and we must overcome the social stigma associated with disabled, which result in a negative impact on the disabled and his family.

We conclude that increasing opportunities for social interactions between disabled and healthy people is the real act of transition to social process acceptance for the various groups of disability. It should be said that the social legislation in Jordanian society represented paradigm shift in the right of disabilities in education and employment. However, the real obstacle to the spread of social integration is the continuing existence of wrong conceptual patterns towards the disabled and the family. The social service and the social worker, therefore, should be the focal point for bridging the barriers to social acceptance for disabled, integrating, and interactions with them like other heathy people.

\section{References:}

1. Al-Rusan, Farouk (1998). Issues and problems in special education: Dar Al-Feker: Amman.

2. Waisbern. S.E. (1980). Parent S reactions after the Birth of Development Disabled Child, American Journal of Mental Definition, vol. 84 No 4.

3. Al-Rihani, Sulaiman (1978). The trends of the parents of mentally disabled children toward mental disability, Journal of University Studies, Jordan, vol. 5 No. 21.

4. Hussein, Muhammad (1988). Males and females teachers' attitudes in the Irbid educational Directorate toward the mobility impairment. Unpublished M.Sc. of Yarmouk University.

5. Higher Council for the Rights of Persons with Disabilities, 2015.

6. Disability Rights Act No. 20 of 2017. 
7. Sarhan, Nazimiya Ahmed.(2006). Social service curriculum for the care of people with disabilities. Arab thought House: Cairo.

8. Abdul Hamid, Abdullah Saber (2018). Social service in the field of disabled people.

9. Jordan General Statistics Department .2017. Disability reality (functional difficulties) in Jordan General population and housing census data.

10. UNIFEM. 2014. Definition and classification of disability types. Technical booklet. Jordan.

11. United Nations. 2012. Department of Economic and Social Affairs.

12. World Health Organization. Middle East region. http://www.emro.who.int/ar/healthtopics/disabilities/index.html.

13. Jordan: disabilities suffer from marginalization. https:/www.dw.com/ar/ Jordan - people with disabilities - suffer from marginalization 